\title{
Abscisic Acid-Induced Autophagy Selectively via MAPK/JNK Signalling Pathway in Glioblastoma
}

\author{
Nan Zhou ${ }^{1} \cdot$ Zixuan Wei $^{1}\left[\right.$ Zengxin $\mathrm{Qi}^{1}{ }^{1} \cdot$ Liang Chen $^{1}(\mathbb{D}$
}

Received: 2 January 2020 / Accepted: 26 May 2020 / Published online: 23 June 2020

(c) The Author(s) 2020

\begin{abstract}
As a widely known plant hormone, Abscisic acid plays an important role in the progress of planting cell and their stress response. Recently, we reported that ABA might play an anti-cancer role in glioma tissues. In the present study, the molecular mechanism of ABA anti-cancer was further explored in glioblastoma cells. By measuring LC3 puncta formation and conversion in glioblastoma cells, inhibiting the autophagic pathway, targeting the essential autophagic modulator beclin 1 with RNA interference, and analysing cellular morphology via transmission electron microscopy, we found that ABA-treated glioblastoma cells exhibited the features of autophagy. Specifically, ABA-induced autophagy in glioblastoma cells was mediated by the MAPK/JNK signalling pathway rather than the PI3K/AKT/mTOR axis. Moreover, the inhibition or knockdown of JNK specifically blocked ABA-induced autophagic cell death. ABA-induced autophagy was further confirmed in tumour-bearing mice and was accompanied by the inhibition of glioma growth in vivo. This report is the first to describe autophagy induced by ABA and mediated by the MAPK/JNK pathway in human cancer cells and tumour-bearing mice. These results may shed some light in new therapeutic strategies of glioma.
\end{abstract}

Keywords Abscisic acid $\cdot$ Autophagy $\cdot$ MAPK/JNK signalling pathway $\cdot$ Glioblastoma

\section{Introduction}

As a plant hormone, Abscisic acid (ABA) has been readily found in fruits and vegetables that can be naturally supplied by the dietary intake (Wasilewska et al. 2008). ABA plays a significant part in the progress of planting cell and their stress response and its medicinal applications have also recently attracted significant attention (Bassaganya-Riera et al. 2010; Li et al. 2011). Although the biosynthetic and metabolic pathways of ABA in animal cells are unknown, many animal and human cells have been shown to produce and release ABA. On account of a series of pioneering studies, Bruzzone et al. illustrated that ABA perform as a regulator between various cell functions, incorporate inflammatory

Electronic supplementary material The online version of this article (https://doi.org/10.1007/s10571-020-00888-1) contains supplementary material, which is available to authorized users.

Liang Chen

chenlianghs@126.com

1 Department of Neurosurgery, Huashan Hospital, Fudan University, Middle Urumqi Road 12, Shanghai 200040, China processes in human granulocytes (Bruzzone et al. 2007), stem cell expansion (Scarfi et al. 2008), the activation of murine microglial cells (Bodrato et al. 2009), insulin release and glucose uptake (Bruzzone et al. 2012). Besides, ABA may also play a vital part in the stress response of mammals by downregulating the gene expression of the corticotrophinreleasing hormone, which is a central driver of the activity of the hypothalamic-pituitary-adrenal system (Qi et al. 2015). ABA Supplementation rescues high-fat diet-induced alterations in hippocampal inflammation (Ribes-Navarro et al. 2019). Recently, it was reported that ABA isolated from honey has antibacterial activity against Helicobacter pylori that links to the progress of the majority of peptic ulcers and several types of gastric cancers (Kim et al. 2017).

Malignant glioblastomas (GBMs) are the most common form of primary brain tumours and are associated with the highest mortality rate (Ostrom et al. 2014). The standard treatment for GBMs is the surgical resection of the tumour followed by concurrent radiation therapy (IR) and chemotherapy with temozolomide (TMZ). Unfortunately, advancements in recent decades have not significantly increased the overall survival of patients with this disease, and it remains an intractable problem to discover 
new therapeutic strategies to combat gliomas. Autophagy, a highly conserved cellular homeostatic process that can either suppress or promote tumours depending on the tumour type and stage is considered a new target for therapeutic interventions in brain tumours (Kaza et al. 2012). Interestingly, both TMZ and IR induce autophagy in glioma cells (Ito et al. 2005; Kanzawa et al. 2004), and pathological studies have shown that the levels of beclin 1 and microtubule-associated protein 1 light chain 3-2 (LC3-2), two biomarkers of autophagy, are lower in GBMs relative to lower-grade astrocytomas and normal brain tissue (Huang et al. 2010; Miracco et al. 2007). Furthermore, high beclin 1 and LC3 levels are associated with improved survival in GBM patients (Aoki et al. 2008; Pirtoli et al. 2009). However, the specific role of autophagy in promoting the survival or death of brain tumours in various therapeutic settings remains unclear.

Notably, Dr. Virginia Livingston (1976) proposed the use of ABA for cancer treatment four decades ago in an issued US patent (WC US3958025[P]). In our recent study, we reported that the ABA levels were twofold higher in low-grade gliomas than in high-grade gliomas. Remarkably, both cellular apoptosis and differentiation were augmented in the glioblastoma cells after ABA treatment. These results suggest that ABA may play an anti-cancer role in glioma by promoting cellular apoptosis and differentiation (Zhou et al. 2016). With respect to therapeutic strategies, glioblastoma cells are well known to be resistant to apoptotic stimuli, and their death occurs via autophagy (Kanzawa et al. 2004; Yao et al. 2003). In this study, we hypothesized that ABA may result in autophagic cell death in glioblastoma cells, making this compound a possible option for the progress of therapeutic drugs for glioma.

\section{Materials and Methods}

\section{Antibodies and Reagents}

The antibodies against beclin 1 (ab55878) and microtubule-associated protein 1 light chain 3 (LC3) (NB1002220) were ordered from Novus Biologicals (LLC, USA). The antibodies recognizing 4E-BP1(\#9644), phospho-4E-BP1(Thr37/46) (\#2855), mTOR(\#2972), phospho-mTOR (Ser2448)(\#2971), p85S6K(\#2708), phospho-p85S6K (Thr412) (\#9234), p70S6K(\#2708), and phospho-p70S6K (Thr389) (\#9234) were obtained from Cell Signaling (Beverly, USA). The anti-GAPDH (KC-5G5) and anti- $\beta$-actin (KC-5A08) antibodies were obtained from Kangcheng (Shanghai, China). All other reagents were ordered from Sigma-Aldrich (St. Louis, USA) unless otherwise indicated.

\section{Cell Culture}

The U87MG and A172 cell lines (Shanghai cell bank) were maintained in DMEM/F12 medium containing 10\% foetal bovine serum (GIBCO, Grand Island, USA), $10 \mu \mathrm{g} / \mathrm{ml}$ streptomycin, and 10 units $/ \mathrm{ml}$ penicillin in a $5 \% \mathrm{CO}_{2}$ humidified atmosphere at $37{ }^{\circ} \mathrm{C}$. U87MG cell line stably expressing LC3 was generated by the transfection of EGFP-LC3 plasmid using Lipofectamine 2000 transfection reagent (Invitrogen). Then cells stably transfected with EGFP-LC3 were selected in DMEM/F12 supplemented with $600 \mu \mathrm{g} / \mathrm{ml} \mathrm{G418}$ (Invitrogen) and 10\% foetal bovine serum. The expression level of LC3 was measured by confocal microscopy.

\section{Immunofluorescence Staining}

As previously described, U87, A172 cells were fixed with 4\% paraformaldehyde in Tris-buffered saline at room temperature for $15 \mathrm{~min}$. After three washes with TBS, samples were incubated with $0.3 \%$ hydrogen peroxide diluted in TBS for half an hour. Then samples were treated with $1 \%$ Triton $\mathrm{X}-100$ for permeabilization followed by overnight incubation with anti-LC3 (1:300) antibody at $4{ }^{\circ} \mathrm{C}$.

\section{Immunohistochemistry (IHC) and Periodic Acid Schiff (PAS) Stain}

Tissues were fixed in $4 \%$ paraformaldehyde at $4{ }^{\circ} \mathrm{C}$ for $48 \mathrm{~h}$, followed by embedding in paraffin and cut into $5 \mu \mathrm{m}$ slices. The paraffin sections were gradient dehydrated in different concentrations of alcohol, and dewaxed in xylene, then the sections were incubated with $3 \% \mathrm{H} 2 \mathrm{O} 2$ and super-blocking reagent in room temperature for $10 \mathrm{~min}$. The sections were subsequently incubated with the following primary antibodies at $4{ }^{\circ} \mathrm{C}$. The next steps of immunohistochemistry stain were detected by ABsin Secondary antibody detection kit (ABsin, abs957) according to the manufacturer's protocols.

\section{Western Blot Analysis}

Radioimmunoprecipitation assay (RIPA) buffer containing protease inhibitors (Roche, Indianapolis, USA) and $1 \mathrm{mM}$ phenylmethylsulfonyl fluoride (Amresco, Solon, USA) was used to prepare cell lysates. Total proteins were separated on $12 \%$ SDS polyacrylamide gels followed by the staining with primary antibodies against LC3, beclin 1, mTOR, 4E-BP1, p85S6K, p70S6K, phospho-mTOR, 
phospho-4E-BP1, phospho-p85S6K, or phospho-p70S6K. GAPDH and $\beta$-actin were used for internal normalization. After the incubation with designated horseradish peroxidase-conjugated secondary antibodies, the bands were imaged using enhanced chemiluminescence (Amersham Bioscience, UK) and the band density was quantified using ImageJ software (NIH).

\section{RNA Interference}

siRNAs targeting beclin 1, JNK, ERK or p38 (GenePharma, Shanghai, China) were transfected into cells to knockdown the target genes. In brief, cells $\left(1 \times 10^{6}\right.$ cells/well $)$ were grown in six-well plates overnight before the treatment with beclin 1 siRNA (5'-CCA CUC UGU GAG GAA UGC ACA GAU A - $3^{\prime}$ ), JNK siRNA (5'-AAA GAA UGU CCU ACC UUC UTT-3'), ERK siRNA (5'-CAA GAG GAU UGA AGU AGA ATT-3'), p38 siRNA (5'-UGA AGA CUG UGA GCU GAA GTT-3'). The control siRNA sequences were: $F$, 5'-UUC UCC GAA CGU GUC ACG UTT-3'; R, 5'-ACG UGA CAC GUU CGG AGA ATT-3'.

Cells grown in 12-well plates were transfected with each siRNA duplex $(1.5 \mathrm{lg})$ using RNAi-Mate (Gene Pharma). The medium was replaced with $1 \mathrm{ml}$ fresh culture medium at $6 \mathrm{~h}$ post-transfection. After $24 \mathrm{~h}$, cells were collected for RNA analyses.

\section{Transmission Electron Microscopy}

Cell pellets were washed three times in PBS and then postfixed in $1 \%$ osmium tetroxide for 1-1.5 h. After three rinses in PBS, samples were dehydrated in graded ethanol series and then transferred to acetone. Subsequently, cells were placed in a 50:50 mixture of acetone and Spurr's epoxy resin for $60 \mathrm{~min}$ followed by overnight incubation with Spurr's epoxy resin at room temperature. Then samples were cured in Beem capsules for $15 \mathrm{~h}$ at $70{ }^{\circ} \mathrm{C}$ and then sectioned into 100 -nm-thick sections with a diamond knife on a Leica UC-7 instrument. The sections stained with uranyl acetate $(2 \%)$ and lead citrate $(0.2 \%)$ were photographed using a transmission electron microscope (Tecnai G2 Spirit BioTWIN, Hillsboro, USA). The de-identified samples were used to record autophagosomes in a minimum of 10 randomly chosen cells. The values reported here are the number of autophagic vacuoles $/ \mu \mathrm{m}^{2} /$ cell.

\section{Statistical Analysis}

The statistical difference was evaluated using one-way ANOVA or two-tailed Student's $t$-test, as appropriate, by
SPSS software (SPSS Software, Chicago, IL, USA). A $p$-value $<0.05$ was considered statistically significant. The data are expressed as mean \pm SEM.

\section{Results}

\section{ABA Actuated Autophagic Cell Death in Glioblastoma Cell Lines}

The level of the microtubule-related protein LC3, an autophagosome protein, was utilized as an indicator of autophagy. To survey the autophagy-inducing capacity of ABA, we initially observed the endogenous expression of LC3 in both U87 and A172 cells by laser confocal microscopy. Incubating the cells with $\mathrm{ABA}$ for $24 \mathrm{~h}$ increased the levels of LC3 puncta compared with controls (Fig. 1). Treatment with rapamycin, a commonly used autophagy inducer, also resulted in the extensive formation of LC3 puncta (Fig. 1a, b). We then tested the impact of ABA on the endogenous conversion of LC3-I to LC3-II and beclin 1 based on Western blotting. The expression levels of LC3-II and Beclin 1 have been expanded greatly in U87 and A172 cells in response to ABA treatment (Fig. 1c, d). Transmission electron microscopy (TEM) is considered the gold standard to assess autophagy. Therefore, we analysed the morphology of ABA-treated cells with TEM. Interestingly, we found that the $\mathrm{ABA}$-treated glioblastoma cells exhibited features of autophagic cell death (Galluzzi et al. 2012). As shown in Fig. 1, after treatment with ABA, the dying cancer cells include intact nuclei, a growing number of autophagic vacuoles, and reduced numbers of cellular organelles (Fig. 1e, f).

\section{ABA Promoted Autophagy Flux by Enhancing Autophagosome Formation in Glioblastoma Cells}

Because ABA promoted autophagosome formation, we assessed the ability of 3-methyladenine (3-MA), a broadly utilized autophagy inhibitor, to attenuate ABA-induced autophagy. As demonstrated in Fig. 2, pre-treatment with 3-MA significantly attenuated ABA-induced increases in LC3II and beclin 1 expression in U87 and A172 cells (Fig. 2a, b). To identify whether these changes were due to increases in autophagosome formation or decreases in autophagic degradation, bafilomycin A1 (Baf A1), which inhibits vacuolar $\mathrm{H}+\mathrm{ATPase}$ and prevents fusion between autophagosomes and lysosomes, was utilized to assess autophagic flux. As shown in Fig. 2, ABA significantly increased the LC3-II levels in U87 (Fig. 2a) and A172 cells (Fig. 2b) in the presence of bafilomycin A1, strongly suggesting that ABA enhanced the formation of autophagosomes. These results also suggested that the autophagic flux induced by ABA was complete. 
A
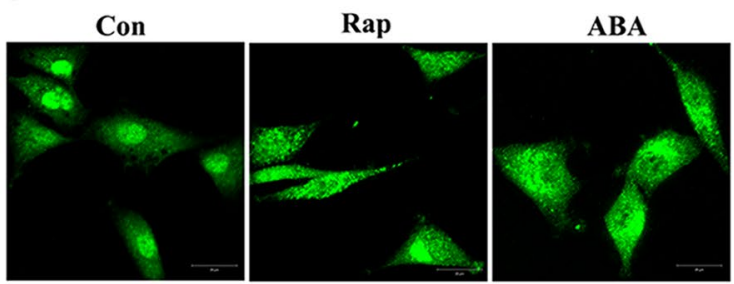

C

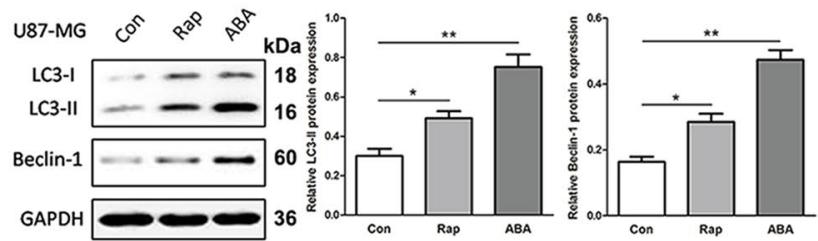

E

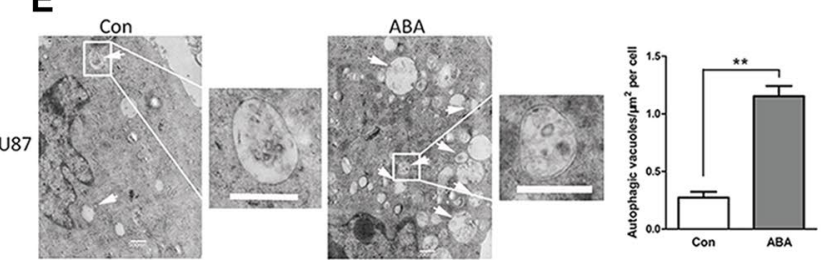

Fig. 1 Abscisic acid inducing autophagy in glioblastoma cells. a, b Immunofluorescence with anti-LC3 antibodies showing endogenous LC3 puncta (green) in cells treated with DMSO (control), rapamycin (Rap $200 \mathrm{nM}$ ) and $200 \mu \mathrm{M}$ abscisic acid (ABA) for $24 \mathrm{~h}$; nuclei (blue) in U87 (a) and A172 cells (b) were visualized with DAPI. c, d Western blotting showing the endogenous conversion of LC3-I to LC3-II and the expression of beclin 1. Quantified by a densitometric analysis relative to GAPDH, the data are demonstrated on the right,

\section{ABA-Induced Autophagy Independent of the PI3K/ AKT/mTOR Signalling Pathway in Glioblastoma Cells}

We first investigated the participation of the PI3K/Akt/ mTOR pathway, a well-known regulatory pathway in autophagy, in ABA-induced autophagy. The phosphorylation statuses of two well-characterized substrates of mTOR, ribosomal S6 protein kinase (p70S6K/p85S6K) and eukaryotic initiation factor $4 \mathrm{E}$-binding protein 1 (4E-BP1), were used as indicators of mTOR activity. As shown in Fig. 3, unlike 3-MA, ABA did not reduce the phosphorylation levels of mTOR or its substrates, ribosomal S6 protein kinase (p70S6K/p85S6K) or eukaryotic initiation factor 4E-binding protein 1 (4E-BP1). We also analysed Akt signalling upstream of mTOR. Consistent with the observed mTOR activity, the phosphorylation status of Akt did not change in response to treatment with ABA (Fig. 3a, b). To further confirm the effect of ABA on mTOR activity, rapamycin was used as a positive
B

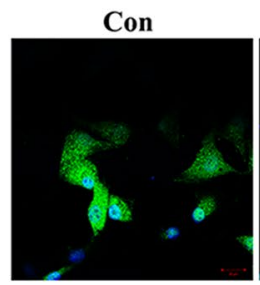

A172

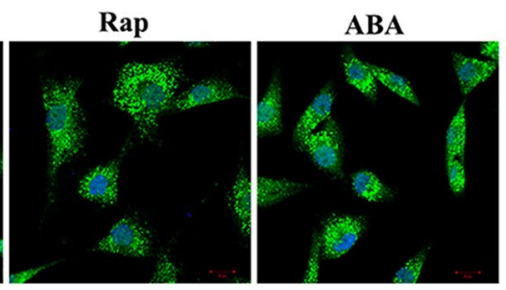

D

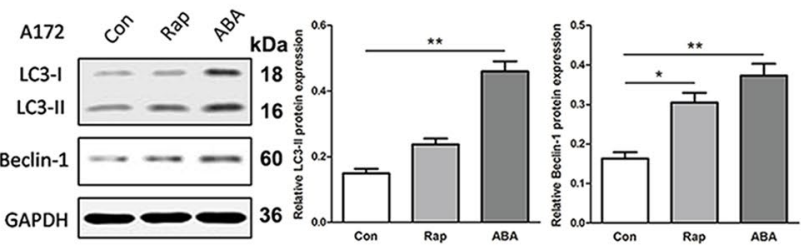

$\mathbf{F}$

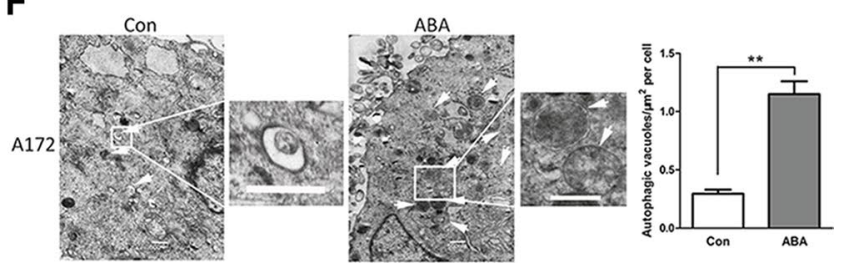

$n=3$. ${ }^{*} P<0.05 * * P<0.01$ compared with controls. e, f Transmission electron microscopy (TEM) images of autophagic vacuoles in isolated cells. Autophagosomes are indicated with arrows. Regions within the boxes are magnified in the insets to indicate the doublemembrane autophagosomes. Histogram values are presented as the mean \pm S.E.M. in a minimum of 10 random cells. $* * P<0.01$ compared with controls. Scale bar, $500 \mathrm{~nm}$

control. As shown in supplementary Fig. 1, rapamycin almost completely blocked the expression of p-mTOR, $\mathrm{p} 70 \mathrm{~S} 6 \mathrm{~K} / \mathrm{p} 85 \mathrm{~S} 6 \mathrm{~K}$ and $4 \mathrm{E}-\mathrm{BP} 1$, whereas ABA did not affect mTOR activity (S-Fig. 1). These results indicate that ABA induced autophagy in an mTOR-independent method in U87 and A172 cell lines.

\section{ABA-Induced Autophagy via the MAPK/JNK Signalling Pathway in Glioblastoma Cells}

MAPK signalling is another pathway that act an important part in autophagic cell death. To determine the association between ABA-induced autophagy and MAPK signalling, the effects of ABA on the phosphorylation of JNK, ERK, and p38 was examined in U87 and A172 cells by Western blotting. Interestingly, in U87 and Al72 cells, ABA treatment resulted in more than twice the expression of phosphorylated JNK and p38 compared with the control (Fig. 4a, b), but did not affect the expression of phosphorylated ERK (Fig. 4a, b). 
A
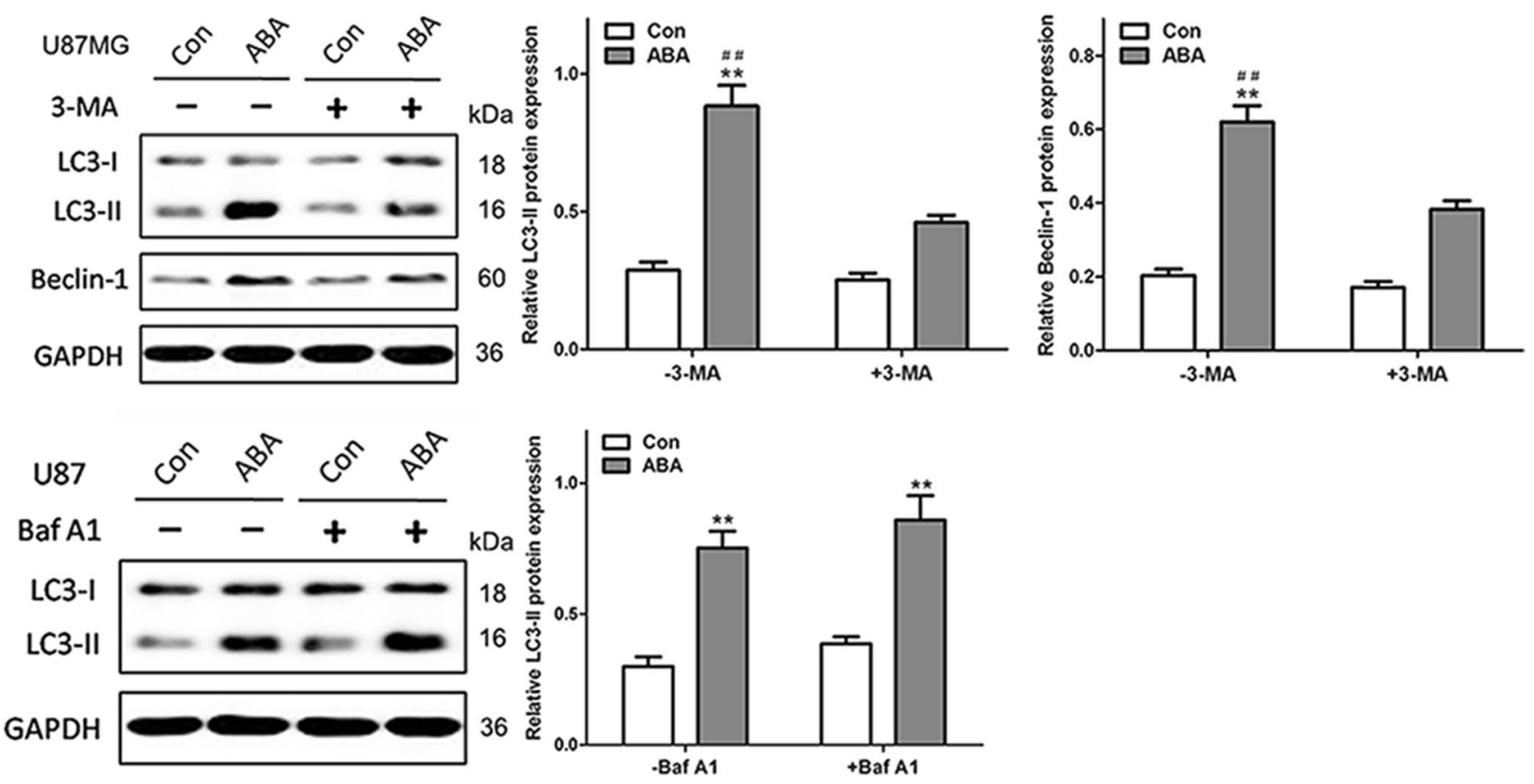

B
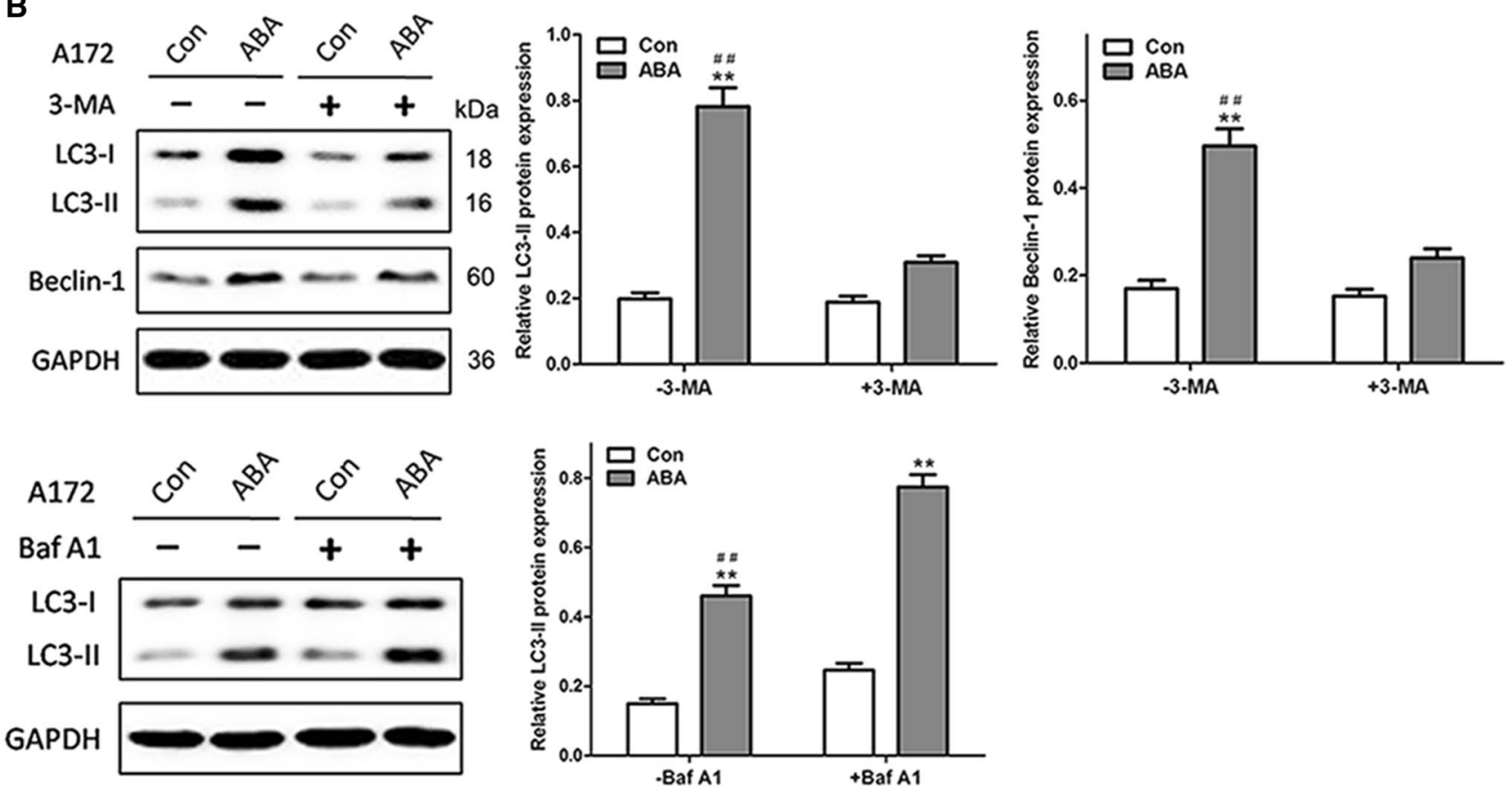

Fig. 2 ABA inducing autophagic flux in glioblastoma cells. ABAinduced autophagy were reduced by the autophagy inhibitor 3-MA and added by enhancing autophagosome formation with bafilomycin A1 both in U87 cells (a) and A172 cells (b). a, b Western blotting at up row indicates the endogenous conversion of LC3-I to LC3-II and the expression of beclin 1 in U87 (a) and A172 cells (b) treated with DMSO (control) or ABA $(200 \mu \mathrm{M})$ for $24 \mathrm{~h}$ in the presence and absence of 3-MA $(10 \mathrm{mM})$. The data quantified by a densitometric analysis relative to GAPDH are shown on the right. $* * P<0.01 \mathrm{com}-$ pared with untreated controls, $n=3$; \#\#P<0.01 compared with 3-MA treatment, $n=3$. Western blotting at low row indicates the conversion of LC3-I to LC3-II in U87 (a) and A172 cells (b) treated with DMSO (control) or ABA $(200 \mu \mathrm{M})$ for $24 \mathrm{~h}$ in the presence and absence of bafilomycin A1 (Baf A1, $400 \mathrm{nM}$ ). The data quantified by a densitometric analysis relative to GAPDH are shown on the right. $* * P<0.01$ compared with untreated controls, $n=3$; \#\#P<0.01 compared with Baf A1 treatment, $n=3$ 


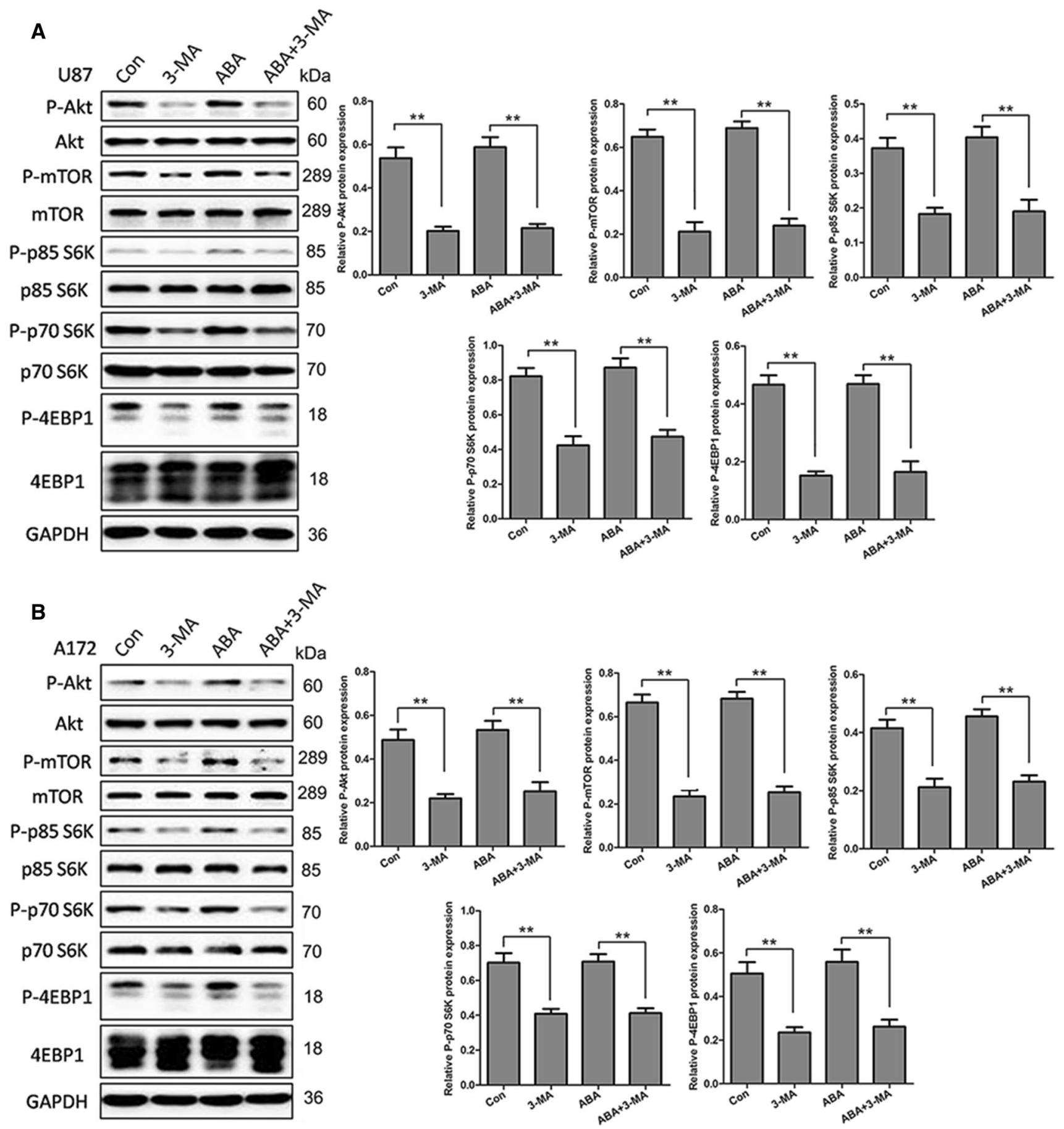

Fig. 3 ABA inducing autophagy independent of the mTOR signal pathway. a U87 and b A172 cells treated with DMSO (control), 3-MA $(10 \mathrm{mM})$ and ABA $(200 \mu \mathrm{M})$ for $24 \mathrm{~h}$ were analysed by Western blotting to measure the levels of total and phospho-Akt, total and
phospho-mTOR, total and phospho-p85S6k, p70S6K and 4E-BP1. The data quantified by a densitometric analysis relative to GAPDH are shown on the right. $* * P<0.01, n=3$ 


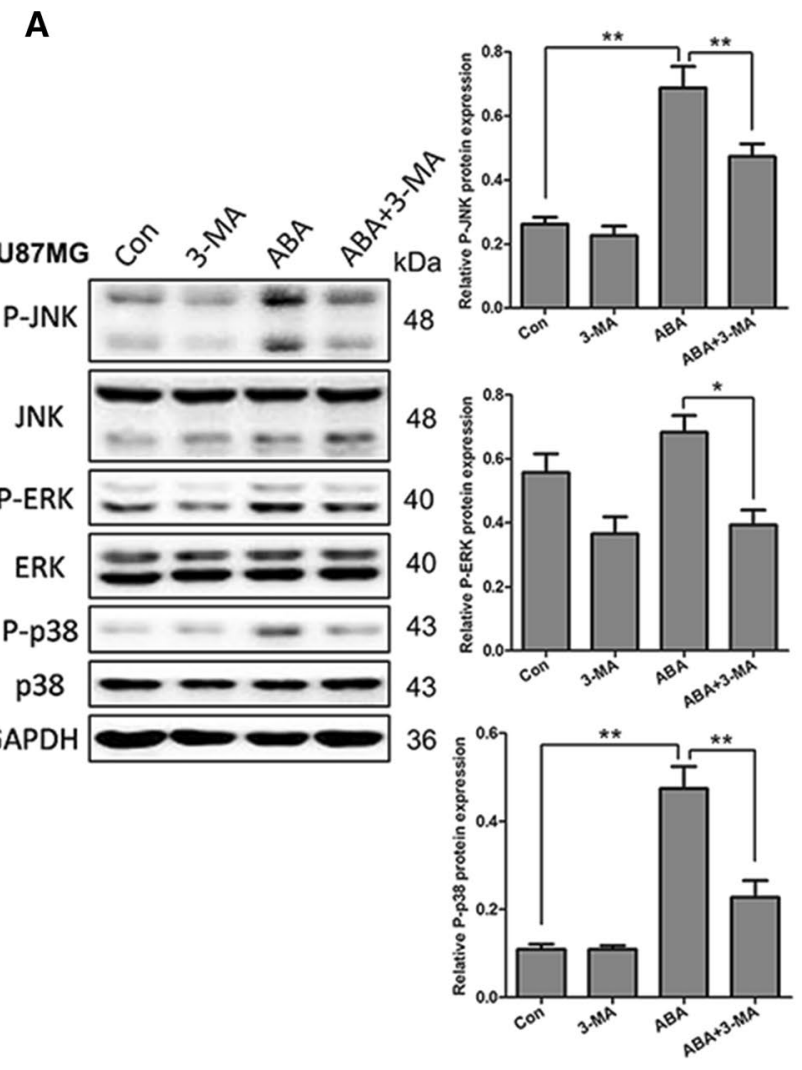

Fig. 4 ABA inducing autophagy via the MAPK signalling pathway. a U87 and b A172 cells treated with DMSO (control), 3-MA (10 mM), $\mathrm{ABA}(200 \mu \mathrm{M})$ and ABA plus 3-MA for $24 \mathrm{~h}$ were analysed by West-

Remarkably, although the addition of the autophagy inhibitor 3-MA did not directly affect the expression of phosphorylated JNK and p38, pre-treatment with 3-MA obviously reduced the ABA-induced expand in p-JNK and p-p38 in U87 and A172 cells (Fig. 4a, b).

\section{Inhibition of MAPK/JNK Signalling Pathway Downregulated ABA-Induced Autophagy in Glioblastoma Cells}

To identify which MAPK signalling pathway that mediates ABA-induced autophagy, U87 and A172 cells were pretreated with inhibitors of JNK (SP600125), ERK (U0126) and p38 (SB203580) for $1 \mathrm{~h}$, followed by the treatment of $200 \mu \mathrm{M}$ ABA for an additional $12 \mathrm{~h}$. As a control, MAPK pathway inhibitors were added, which significantly reduced the increases in p-ERK, p-JNK, and p-p38 induced by ABA (S-Fig. 2). Interestingly, only the inhibition of JNK with

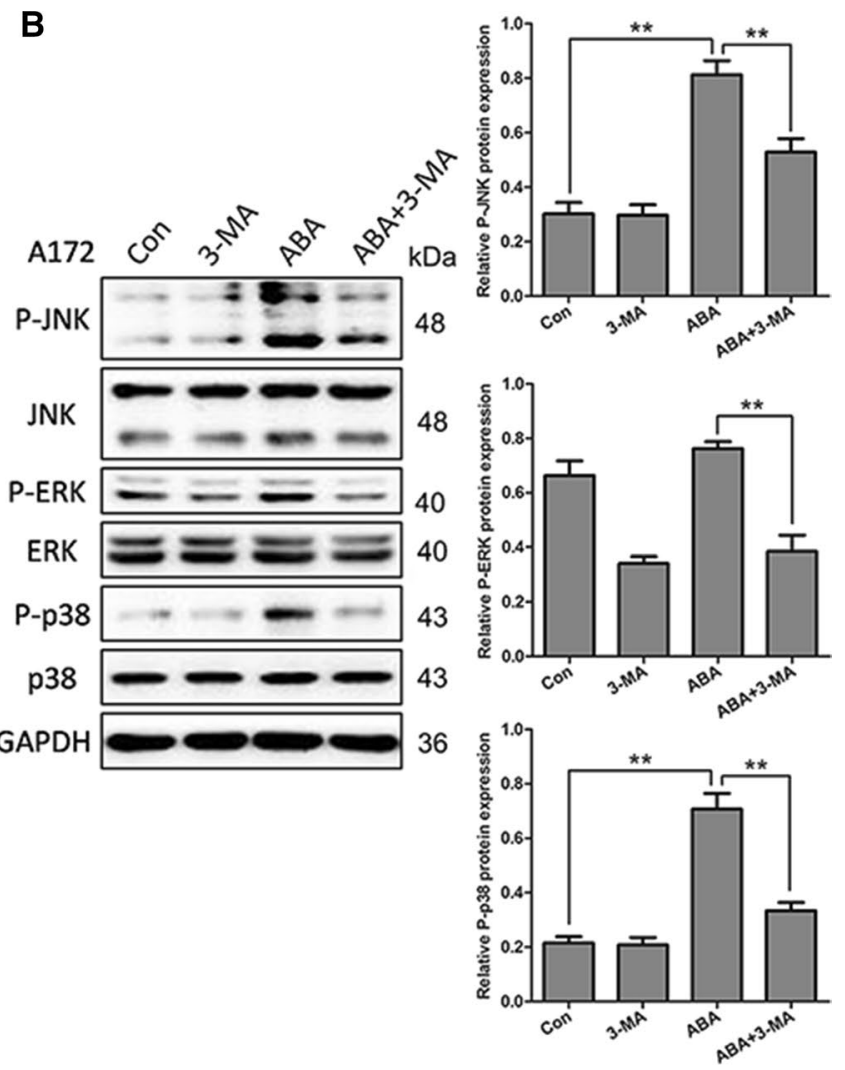

ern blotting to measure the levels of total and phosphorylated JNK, ERK and $\mathrm{p} 38$. The data quantified by a densitometric analysis relative to GAPDH are shown on the right. $* P<0.05, n=3$; $* * P<0.01, n=3$

SP600125 reduced the ABA-induced expression of LC3-II and beclin 1 to $50 \%$ and $60 \%$ of the control levels, respectively, in U87 and A172 cells (Fig. 5a-d). Conversely, inhibitors of ERK and p38 did not affect the expression of beclin 1 and LC3-II in either U87 or A172 cells (Fig. 5a-d). These data indicate that ABA induced autophagy specifically via the JNK signalling pathway in glioblastoma cells.

\section{Knockdown of Autophagy-Related Genes did not Affect the Expression of Key Proteins in the MAPK Signalling Pathway}

Beclin 1 is important for the signalling pathways participation in autophagosome formation. Depicted in Fig. 6a, b, transfection with small interfering RNAs (siRNAs) specific to beclin 1 markedly decreased the number of autophagic vacuoles in U87 and A172 cells, as revealed by TEM. Furthermore, the knockdown of beclin 1 significantly decreased 
A

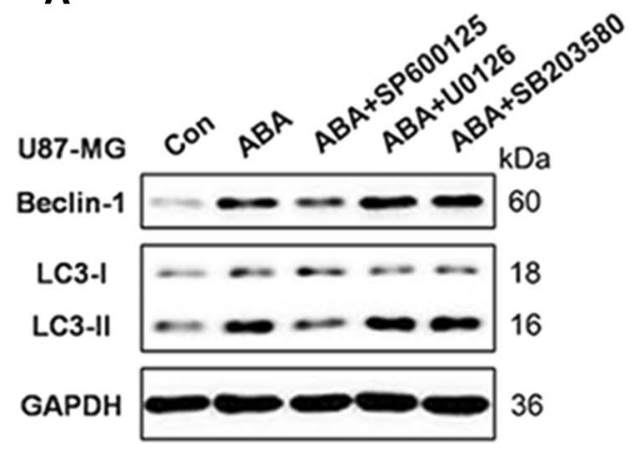

C

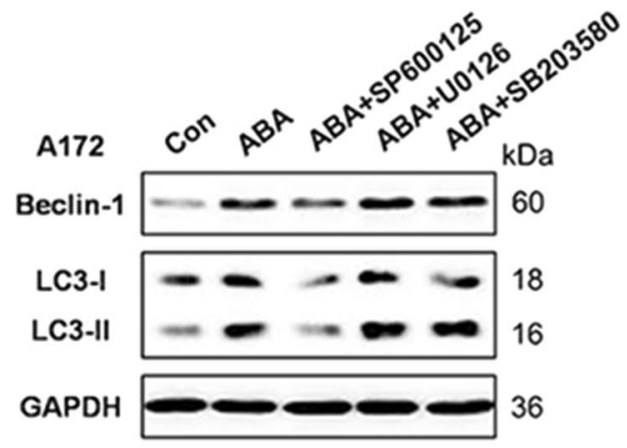

B

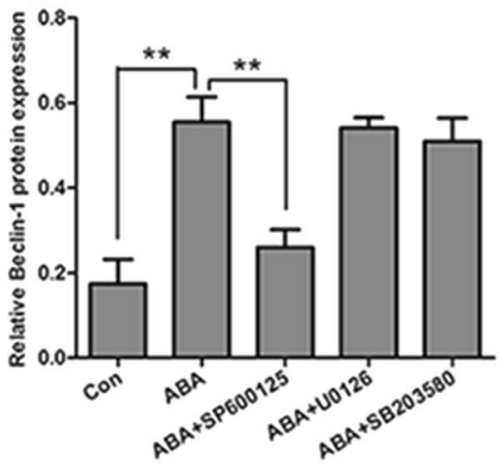

D

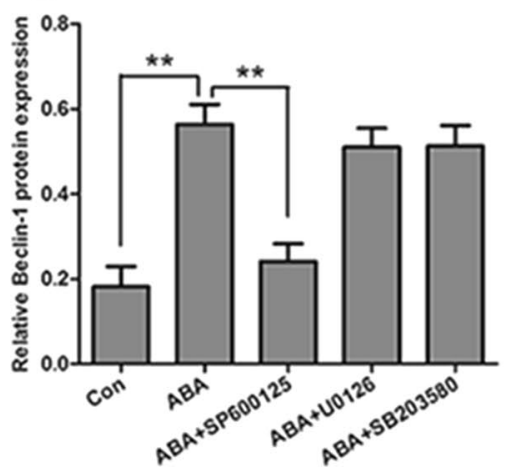

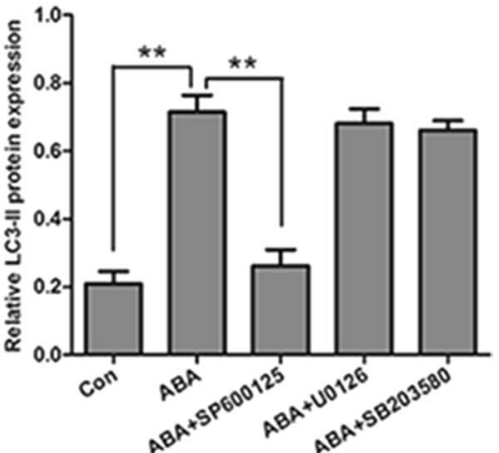

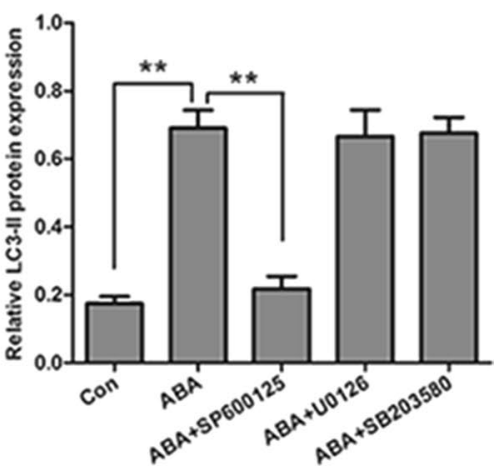

Fig. 5 Causal relationship between the MAPK/JNK signalling pathway and ABA-induced autophagy. a, b U87 and c, d A172 cells treated with DMSO (control) or pre-treated with the JNK inhibitor SP600125 $(25 \mu \mathrm{M})$, ERK inhibitor U0126 $(20 \mu \mathrm{M})$ and p38 inhibi- tor SB203580 for $1 \mathrm{~h}$, followed by treatment with ABA $(200 \mu \mathrm{M})$ for $24 \mathrm{~h}$ were analysed by Western blotting to measure the levels of beclin 1 and LC3-II. The data quantified by a densitometric analysis relative to GAPDH are shown on the right. $* * P<0.01, n=3$ the standard of endogenous beclin 1 and LC3-II proteins induced by ABA (Fig. 6c, d). However, the knockdown of beclin 1 did not affect the ABA-induced expression of phosphorylated JNK, ERK and p38 (Fig. 6e, f), indicating that the autophagy machinery acts downstream of the MAPK signalling pathway.

\section{Causal Relationship Between the MAPK/JNK Signal Pathway and ABA-Induced Autophagy}

To further characterize the causal relationship between the MAPK/JNK signalling pathway and ABA-induced autophagy, U87 cells and A172 cells were transfected with JNK, ERK and p38-specific siRNA or nonspecific siRNA. As shown in Fig. 7, JNK knockdown dramatically reduced the number of autophagic vacuoles induced by ABA in both U87 and A172 cells, as measured by TEM (Fig. 7a, b).
Silencing JNK also significantly decreased the expression of beclin 1 and LC3-II in both U87 and A172 cells, as revealed by a Western blot (Fig. 7c, d). However, the knockdown of ERK or p38 neither affected the number of autophagic vacuoles nor the expression levels of beclin 1 and LC3-II in U87 and A172 cells (S-Figs. 3 and 4). These results suggest that the MAPK/JNK signalling pathway is causally related to ABA-induced autophagic cell death in glioblastoma cell lines.

\section{ABA Elevated Autophagic CELL DEATH and Inhibited Tumour Growth in Tumour-Bearing Mice}

On account of the ability of ABA to induce the autophagy in glioblastoma cells, then we tried the effects of ABA with tumour allografts in Balb/c mice. Specifically, Balb/c mice were subcutaneously injected with U87 cells. After 7 days 

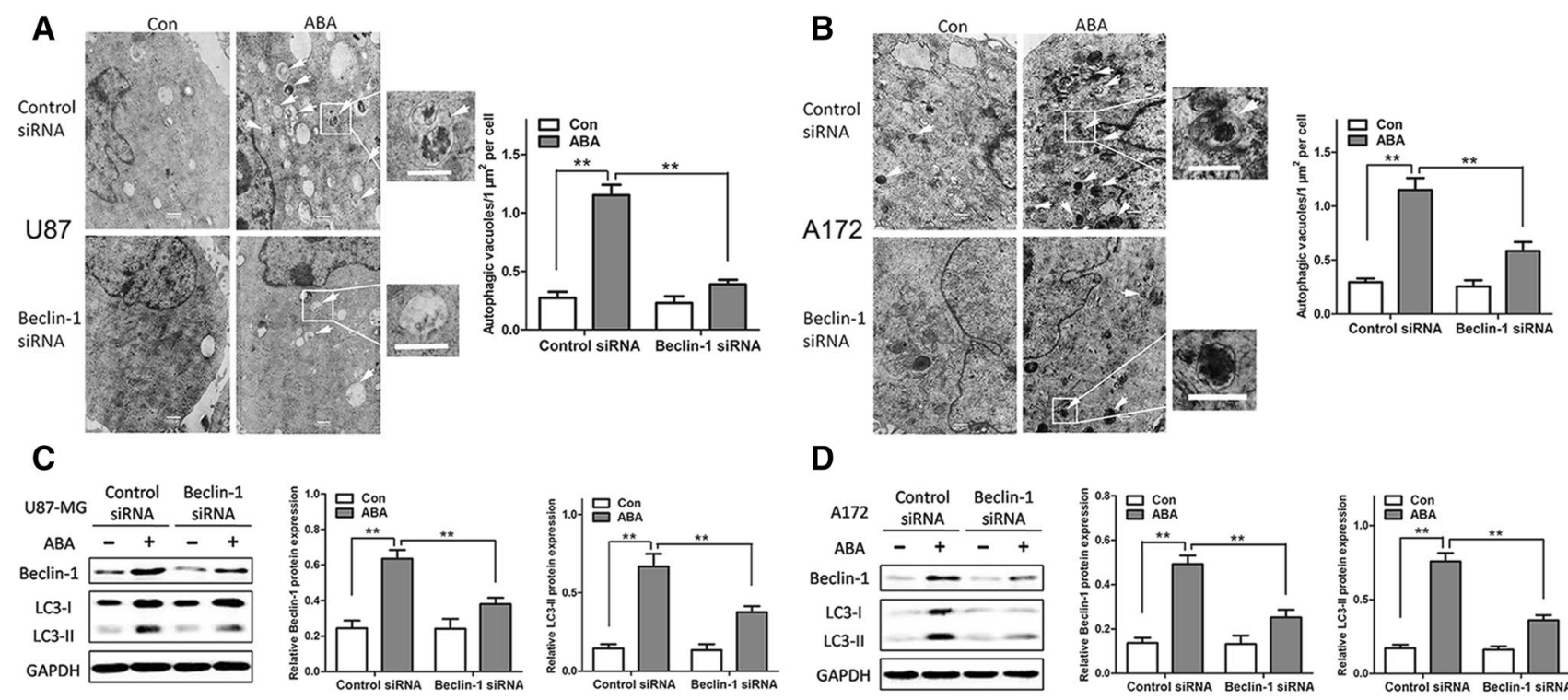

D
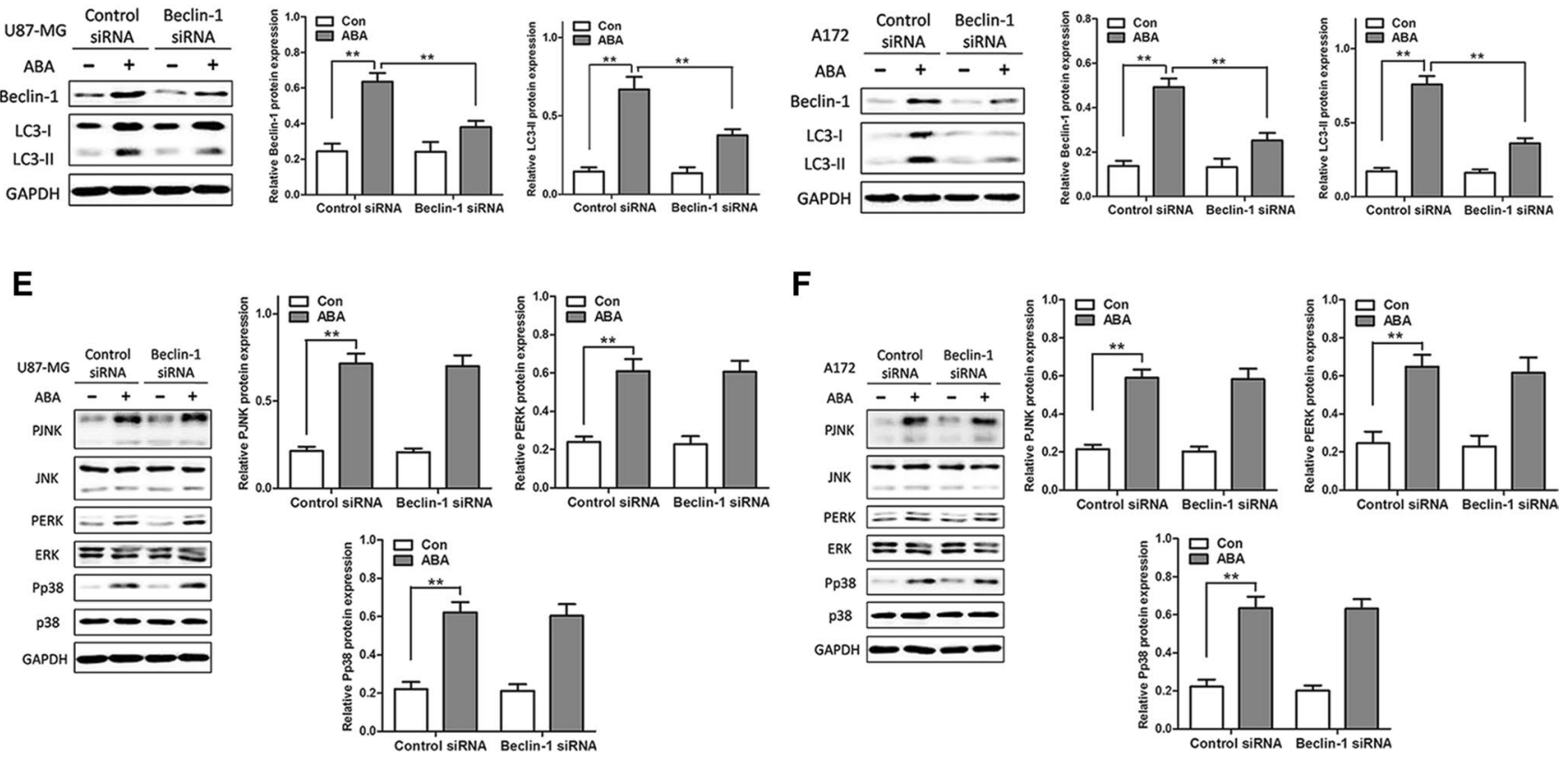

$\mathbf{F}$

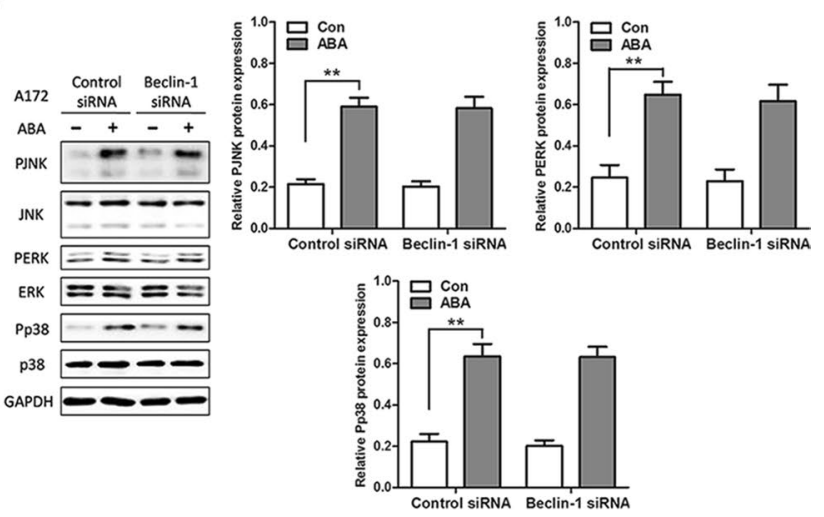

Fig. 6 ABA inducing autophagy and activates the MAPK signalling pathway independent of beclin 1 RNA interference (siRNA) in glioblastoma cells. a, b Representative transmission electron microscope (TEM) images of autophagic vacuoles (arrows). Regions within the boxes are magnified in the insets indicating the double-membrane autophagosomes. Scale bars: $500 \mathrm{~nm}$. Right panels in a and b show

the mice were given injections of control or ABA every day. Interestingly, body weight did not significantly differ between this two group, figuring that ABA treatment had a receivable safety range (Fig. 8a). Although ABA exhibited anti-tumour effects in tumour-bearing mice compared with controls, these effects were less than those of temozolomide. Moreover, ABA-treated mice exhibited an obvious diminution in tumour mass compared with the control group in three weeks (Fig. 8b). ABA-induced autophagy was further revealed by increases in the expression levels of LC3-II and beclin 1 in ABA-treated, tumour-bearing mice detected by Western blotting (Fig. 8c). Moreover, an immunohistochemical analysis further confirmed increases in LC3 expression in ABA-treated tumours, indicating the occurrence of autophagy (Fig. 8d). Thus, ABA effectively

the quantification of ABA-induced autophagic vacuoles $/ \mu \mathrm{m}^{2} /$ cell with or without siRNA against beclin 1 in a U87 MG and b A172 cells. c-f ABA-induced expression of MAPK signalling pathway effectors independent of beclin 1 silencing in $\mathrm{U} 87(\mathbf{c}, \mathbf{e})$ and A172 (e, f) cells measured by Western blotting. Values represent the mean \pm SEM. $* * P<0.01, n=3$

enhanced autophagy in vivo and was accompanied by inhibited tumour growth in a tumour-bearing animal model.

\section{Discussion}

In the present study, the plant hormone ABA provoke autophagic cell death in glioblastoma cell lines via the JNK-MAPK signalling pathway. Furthermore, ABA inhibited tumour growth and enhances autophagy in an allograft model of glioma.

In plant, ABA has emerged as key players in the induction of autophagy under stress conditions. (Kulich and Zarsky 2014; Vanhee and Batoko 2011). Initially, we report that ABA induces autophagy in human cancer cell lines and 


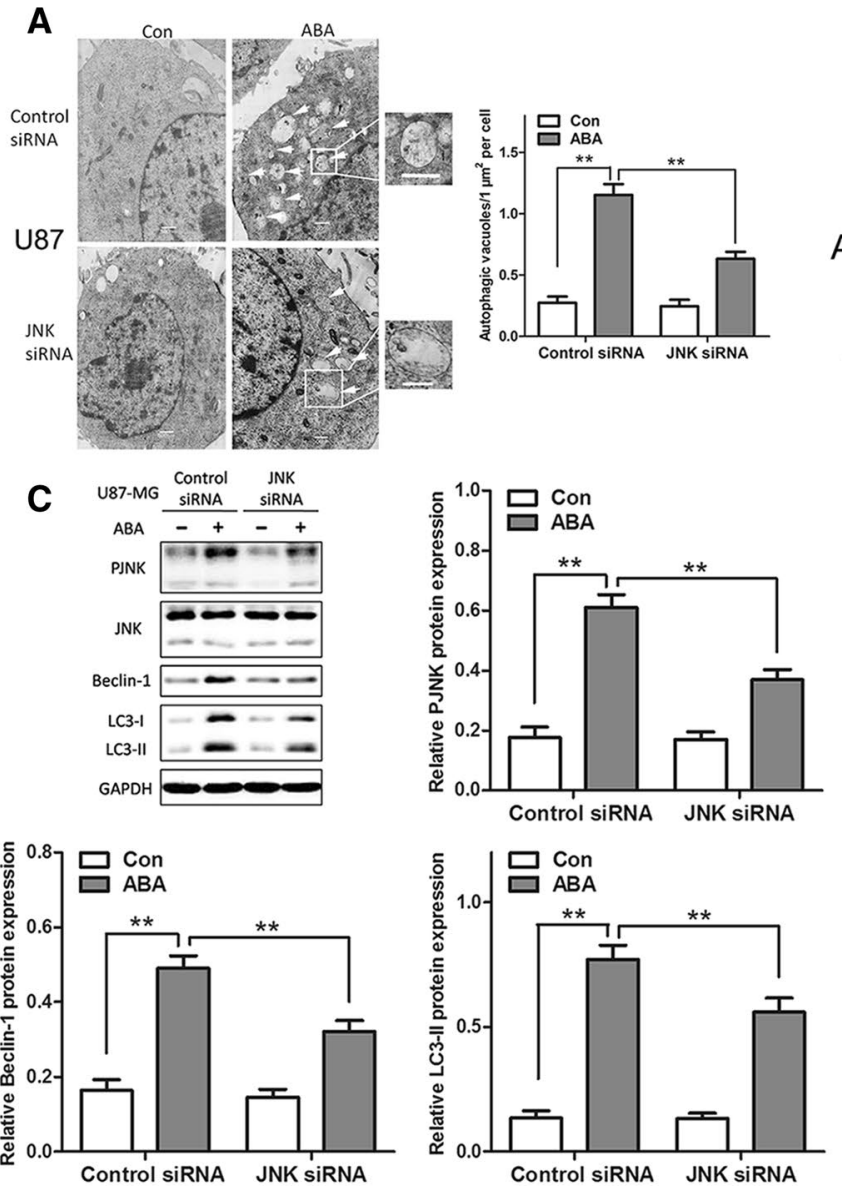

Fig. 7 ABA inducing autophagy in glioblastoma cells independent of MAPK RNA interference (siRNA). a, b Representative transmission electron microscope (TEM) images of autophagic vacuoles (arrows). Regions within the boxes are magnified in the insets indicating the double-membrane autophagosomes. Scale bars: $500 \mathrm{~nm}$. Right panels

in an animal model. Furthermore, by targeting the essential autophagic modulator beclin 1 with RNAi to inhibit autophagy and assessing the morphology of treated cells via $\mathrm{EM}$, we found that ABA-treated glioblastoma cells exhibited features of either autophagic cell death as defined by the Nomenclature Committee on Cell Death (Galluzzi et al. 2012) or autophagy-associated cell death (AACD) as identified by Tasdemir et al. (Vicencio et al. 2008). These results are in accordance with the works before depicted high levels
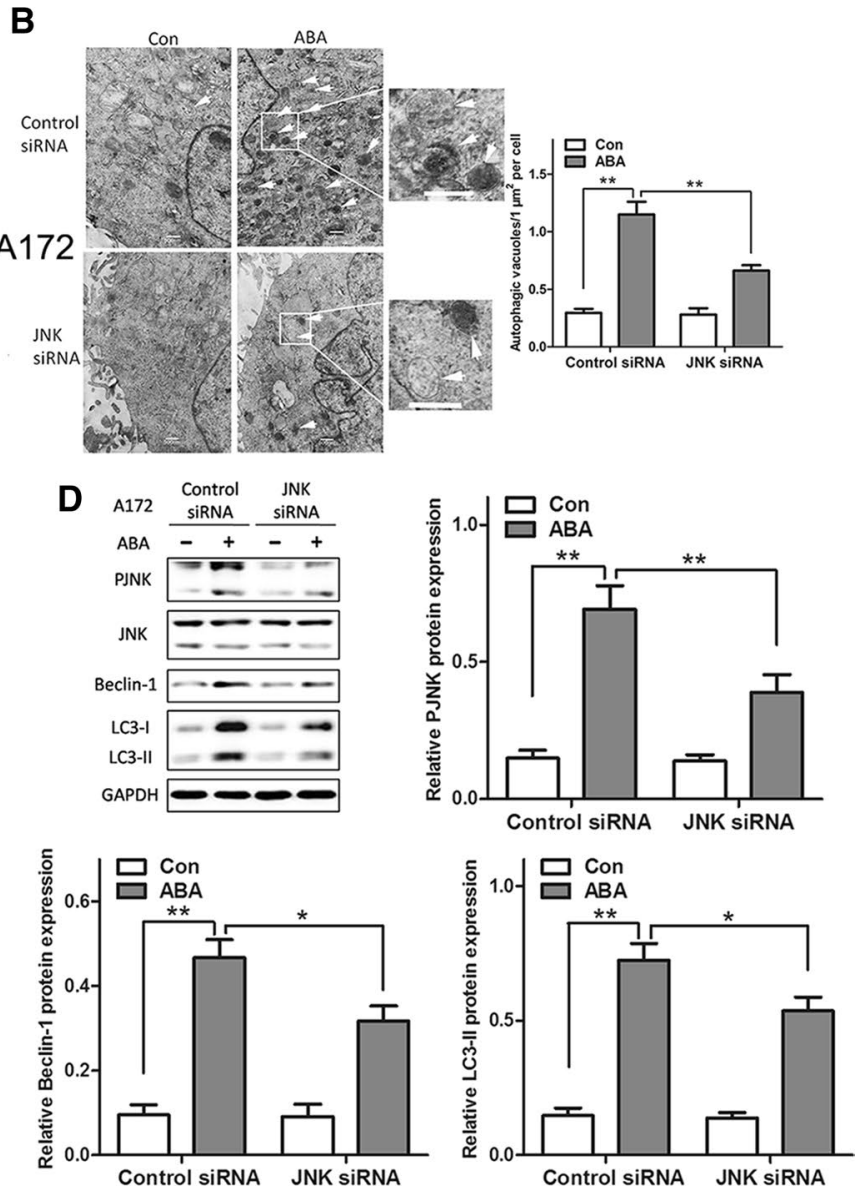

in $\mathbf{a}$ and $\mathbf{b}$ show the quantification of ABA-induced autophagic vacuoles $/ \mu \mathrm{m}^{2} /$ cell in U87 MG and A172 cells with or without siRNA. c, d ABA-induced expression of beclin 1 and LC3-II with or without JNK silencing in $\mathbf{c}$ U87 and d A172 cells as measured by Western blotting. Values represent the mean $\pm \mathrm{SEM} ; * * P<0.01, n=3$

of autophagy induce cell death rather than supporting cell survival in glioma (Shchors et al. 2015; Shipman 2015). Among GBM patients, relatively higher levels of autophagy are related to preferable survival and prognosis (Aoki et al. 2008). Moreover, Chen et al. recently reported that the microRNA miR-129 is an effectively inducer of autophagy, and the intratumoural injection of miR-129 lentivirus significantly constrained tumour growth (Chen et al. 2016). ABAinduced autophagic cell death is of interest as a therapeutic 
strategy for GBM because the stimulation of autophagy is considered a potential therapeutic approach. However, information regarding the use of autophagy-enhancing agents in clinical trials for the treatment of glioblastoma is limited. Specifically, mammalian target of rapamycin inhibitors are approved by the US Food and Drug Administration (FDA) for cancer therapy (Huang and Fingar 2014), and the combination of mTOR inhibitors with TMZ during radiotherapy to trigger autophagic cell death is thought to be a promising treatment approach (Koukourakis et al. 2016). A phase II study of temsirolimus, an analogue of the allosteric mTOR inhibitor rapamycin, showed that this agent was clinically effective in $30 \%$ patients treated for recurrent glioblastoma (Galanis et al. 2005). Hainsworth et al. administered BVZ with everolimus, another inhibitor of mTOR, after radiochemotherapy to 68 glioblastoma patients; the results showed that this regimen improved the progression-free survival of patients (Hainsworth et al. 2012). However, another phase II study of one hundred patients did not distinguish any useful impact on survival in patients with glioblastoma (Ma et al. 2015). Interestingly, Shipiman et al. recently showed that the imipramine and the ticlopidine synergistically induced autophagy and slow down glioma progression in mice (Shchors et al. 2015; Shipman 2015).

To elucidate the molecular mechanisms underlying ABAinduced autophagy, we studied possible signalling pathways in glioblastoma cells. In contrast to a previous study, in which the PI3K/AKT/mTOR signalling pathway was shown to be involved in anti-cancer agent-induced autophagy in glioma (Sami and Karsy 2013), we found that ABA-induced autophagy in glioblastoma cells is independent of the PI3K/
AKT/mTOR signalling pathway. Instead, we discovered that the MAPK/JNK signalling pathway is essential for ABAinduced autophagy. The discrepancies between these findings may be due to differences in the cancer type and doses used in the different experimental models. The MAPK/ JNK pathway was recently reported to potentially regulate autophagy in glioma (Zhou et al. 2015) and was also reported to control the balance of apoptosis and autophagy in response to chemotherapeutic agents. Specifically, the JNK signal transduction pathway plays a crucial part in autophagic cell death and defence mechanisms. Liu et al. showed that palmitate promotes autophagy and apoptosis through ROS-dependent JNK and p38 MAPK. Here, we discovered that ABA promoted the expression of phosphorylated JNK, ERK and p38, but only the knockdown of JNK blocked ABA-induced autophagy, and neither ERK nor p38 knockdown affected ABA-induced autophagy. These outcomes were in line with the results of the studies before showing that autophagy is regulated by the JNK pathway. Moreover, arsenic trioxide, evodiamine, and the downregulation of protein kinase CK2 can reportedly induce autophagic cell death by modulating the MAPK signalling pathway in human glioblastoma cells (Chiu et al. 2011; Kanzawa et al. 2005; Liu et al. 2013; Olsen et al. 2012).

In conclusion, this report is the first to show that treatment with the phytohormone $\mathrm{ABA}$ results in autophagic cell death in human cancer cells and tumour-bearing mice and that this effect is mediated by the MAPK/JNK pathway. These results may provide a promising avenue for the development of glioma therapies. 

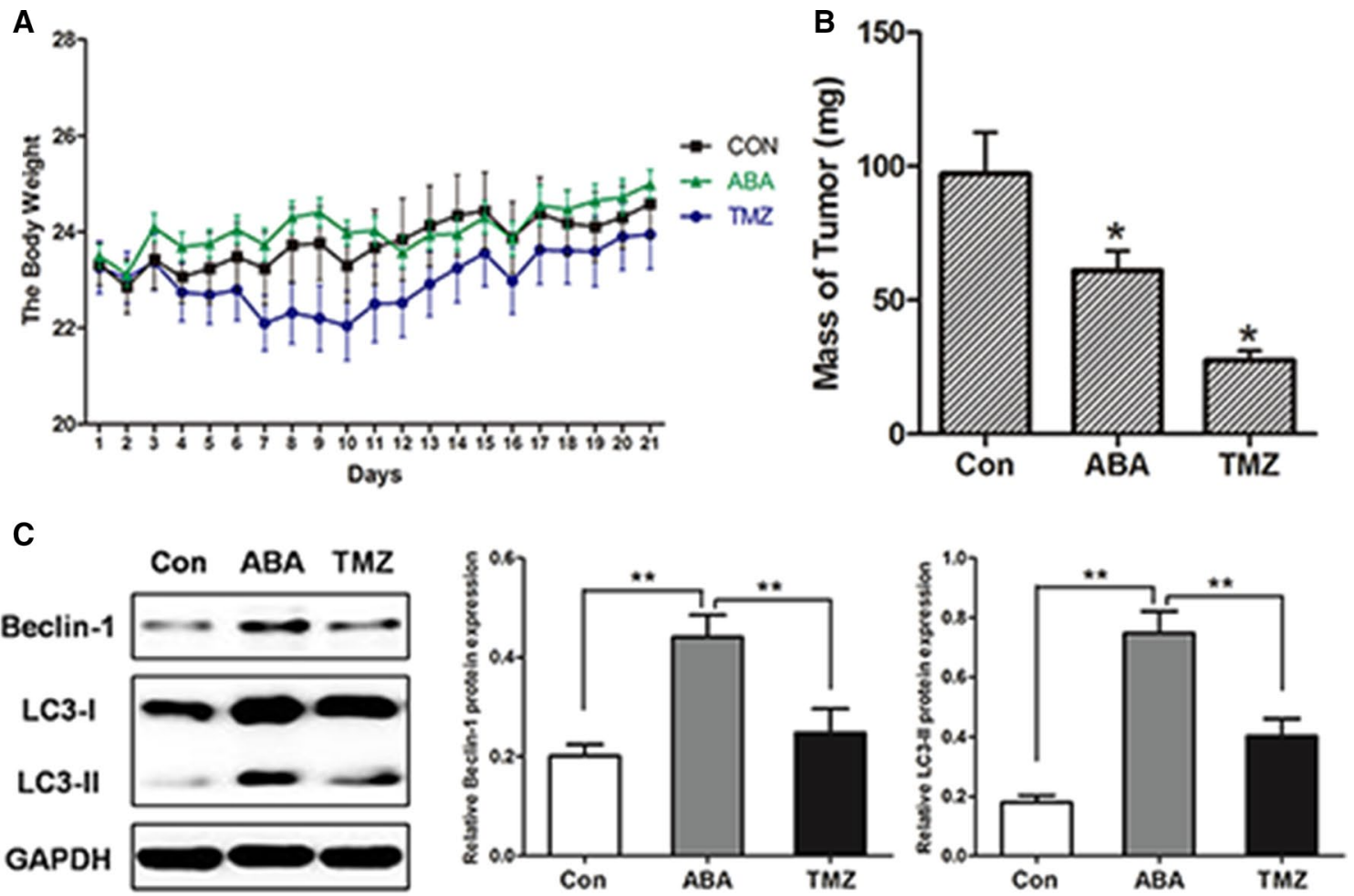

D
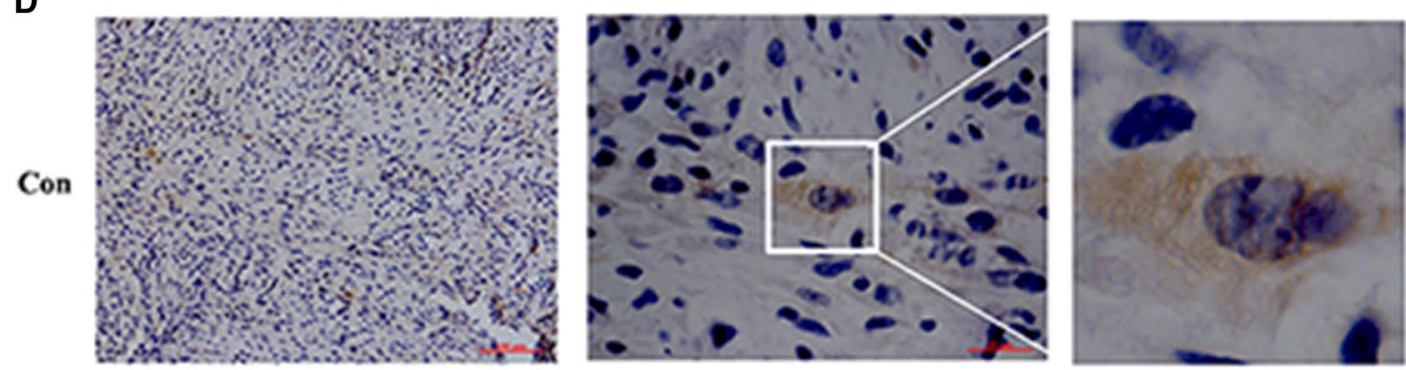

ABA
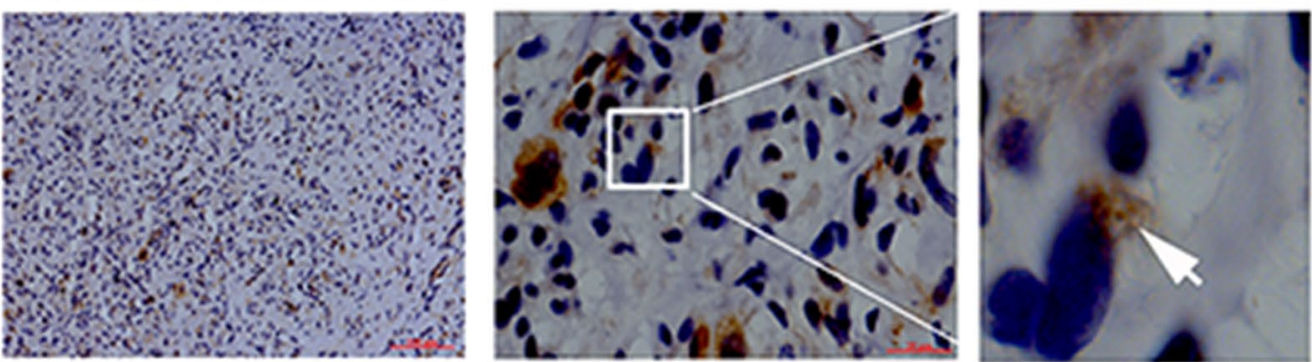

TMZ
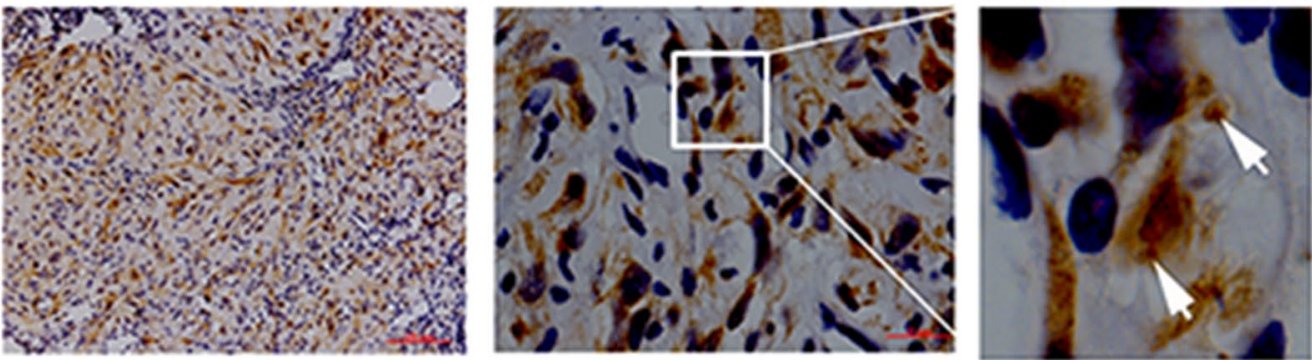
4Fig. 8 ABA inhibiting tumour growth in an allograft model of glioma. Balb/c nude mice were injected with U87 cells and then treated with DMSO (7 mice, negative control) or $15 \mathrm{mg} / \mathrm{kg}$ temozolomide (TMZ) (10 mice, positive control) and $60 \mathrm{mg} / \mathrm{kg} \mathrm{ABA} \mathrm{(10}$ mice) once daily for 21 days. a The body weights of control, temozolomide- and ABA-treated mice over 21 days. b Tumours were collected after 21 days; $* P<0.05$ compared with control. c Levels of beclin 1 and LC3-II autophagic tumour tissue from a tumour-bearing mouse model as analysed by Western blotting. The data quantified by a densitometric analysis relative to GAPDH are shown on the right; $* * P<0.01, n=3$. d LC 3 expression in tumour tissues as measured by immunocytochemistry. Regions within the boxes are magnified in the insets to indicate the puncta-like staining of LC3

Acknowledgements Shanghai Sailing Programe (17YF1426500), National Natural Science Foundation of China (81702175), National Natural Science Foundation of China (81702461). The authors thank Dr. Lei Fang and Ms. Xiuhong Qi for their technical assistance.

Author Contributions NZ designed the study, performed the research and wrote the manuscript. ZXW edited the manuscript. ZXQ analysed the data and performed the research. LC designed and reviewed the manuscript.

\section{Compliance with Ethical Standards}

Conflict of interest The authors confirm that there are no conflicts of interest.

Open Access This article is licensed under a Creative Commons Attribution 4.0 International License, which permits use, sharing, adaptation, distribution and reproduction in any medium or format, as long as you give appropriate credit to the original author(s) and the source, provide a link to the Creative Commons licence, and indicate if changes were made. The images or other third party material in this article are included in the article's Creative Commons licence, unless indicated otherwise in a credit line to the material. If material is not included in the article's Creative Commons licence and your intended use is not permitted by statutory regulation or exceeds the permitted use, you will need to obtain permission directly from the copyright holder. To view a copy of this licence, visit http://creativecommons.org/licenses/by/4.0/.

\section{References}

Aoki H et al (2008) Monitoring autophagy in glioblastoma with antibody against isoform $\mathrm{B}$ of human microtubule-associated protein 1 light chain 3. Autophagy 4:467-475

Bassaganya-Riera $\mathbf{J}$ et al (2010) Mechanisms of action and medicinal applications of abscisic Acid. Curr Med Chem 17:467-478

Bodrato $\mathrm{N}$ et al (2009) Abscisic acid activates the murine microglial cell line N9 through the second messenger cyclic ADP-ribose. J Biol Chem 284:14777-14787. https://doi.org/10.1074/jbc.M8026 04200

Bruzzone S et al (2007) Abscisic acid is an endogenous cytokine in human granulocytes with cyclic ADP-ribose as second messenger. Proc Natl Acad Sci USA 104:5759-5764. https://doi.org/10.1073/ pnas.0609379104

Bruzzone S et al (2012) The plant hormone abscisic acid increases in human plasma after hyperglycemia and stimulates glucose consumption by adipocytes and myoblasts. FASEB J 26:1251-1260. https://doi.org/10.1096/fj.11-190140
Chen X et al (2016) MiR-129 triggers autophagic flux by regulating a novel Notch-1/ E2F7/Beclin-1 axis to impair the viability of human malignant glioma cells. Oncotarget 7:9222-9235. https:// doi.org/10.18632/oncotarget.7003

Chiu HW, Ho YS, Wang YJ (2011) Arsenic trioxide induces autophagy and apoptosis in human glioma cells in vitro and in vivo through downregulation of survivin. J Mol Med (Berlin, Germany) 89:927-941. https://doi.org/10.1007/s00109-011-0763-1

Galanis E et al (2005) Phase II trial of temsirolimus (CCI-779) in recurrent glioblastoma multiforme: a North Central Cancer Treatment Group Study. J Clin Oncol 23:5294-5304. https://doi.org/10.1200/ jco.2005.23.622

Galluzzi L et al (2012) (2012) Molecular definitions of cell death subroutines: recommendations of the Nomenclature Committee on Cell Death. Cell Death Differ 19:107-120. https://doi. org/10.1038/cdd.2011.96

Hainsworth JD, Shih KC, Shepard GC, Tillinghast GW, Brinker BT, Spigel DR (2012) Phase II study of concurrent radiation therapy, temozolomide, and bevacizumab followed by bevacizumab/everolimus as first-line treatment for patients with glioblastoma. Clin Adv Hematol Oncol H\&O 10:240-246

Huang K, Fingar DC (2014) Growing knowledge of the mTOR signaling network. Semin Cell Dev Biol 36:79-90. https://doi. org/10.1016/j.semcdb.2014.09.011

Huang X, Bai HM, Chen L, Li B, Lu YC (2010) Reduced expression of LC3B-II and Beclin 1 in glioblastoma multiforme indicates a down-regulated autophagic capacity that relates to the progression of astrocytic tumors. J Clin Neurosci 17:1515-1519. https://doi. org/10.1016/j.jocn.2010.03.051

Ito H, Daido S, Kanzawa T, Kondo S, Kondo Y (2005) Radiationinduced autophagy is associated with LC3 and its inhibition sensitizes malignant glioma cells. Int J Oncol 26:1401-1410

Kanzawa T, Germano IM, Komata T, Ito H, Kondo Y, Kondo S (2004) Role of autophagy in temozolomide-induced cytotoxicity for malignant glioma cells. Cell Death Differ 11:448-457. https:// doi.org/10.1038/sj.cdd.4401359

Kanzawa T, Zhang L, Xiao L, Germano IM, Kondo Y, Kondo S (2005) Arsenic trioxide induces autophagic cell death in malignant glioma cells by upregulation of mitochondrial cell death protein BNIP3. Oncogene 24:980-991. https://doi.org/10.1038/ sj.onc. 1208095

Kaza N, Kohli L, Roth KA (2012) Autophagy in brain tumors: a new target for therapeutic intervention. Brain Pathol (Zurich, Switzerland) 22:89-98. https://doi.org/10.1111/j.1750-3639.2011.00544 . $\mathrm{X}$

Kim S, Hong I, Woo S, Jang H, Pak S, Han S (2017) Isolation of abscisic acid from Korean acacia honey with anti-helicobacter pylori activity. Pharmacogn Mag 13:S170-S173. https://doi. org/10.4103/0973-1296.210166

Koukourakis MI, Mitrakas AG, Giatromanolaki A (2016) Therapeutic interactions of autophagy with radiation and temozolomide in glioblastoma: evidence and issues to resolve. Br J Cancer 114:485-496. https://doi.org/10.1038/bjc.2016.19

Kulich I, Zarsky V (2014) Autophagy-related direct membrane import from ER/cytoplasm into the vacuole or apoplast: a hidden gateway also for secondary metabolites and phytohormones? Int J Mol Sci 15:7462-7474. https://doi.org/10.3390/ijms 15057462

Li HH, Hao RL, Wu SS, Guo PC, Chen CJ, Pan LP, Ni H (2011) Occurrence, function and potential medicinal applications of the phytohormone abscisic acid in animals and humans. Biochem Pharmacol 82:701-712. https://doi.org/10.1016/j.bcp.2011.06.042

Liu AJ et al (2013) Evodiamine, a plant alkaloid, induces calcium/ JNK-mediated autophagy and calcium/mitochondria-mediated apoptosis in human glioblastoma cells. Chem Biol Interactions 205:20-28. https://doi.org/10.1016/j.cbi.2013.06.004 
Ma DJ et al (2015) A phase II trial of everolimus, temozolomide, and radiotherapy in patients with newly diagnosed glioblastoma: NCCTG N057K. Neuro-oncology 17:1261-1269. https://doi. org/10.1093/neuonc/nou328

Miracco C et al (2007) Protein and mRNA expression of autophagy gene Beclin 1 in human brain tumours. Int J Oncol 30:429-436

Olsen BB, Svenstrup TH, Guerra B (2012) Downregulation of protein kinase CK2 induces autophagic cell death through modulation of the mTOR and MAPK signaling pathways in human glioblastoma cells. Int J Oncol 41:1967-1976. https://doi.org/10.3892/ ijo.2012.1635

Ostrom QT et al (2014) CBTRUS statistical report: primary brain and central nervous system tumors diagnosed in the United States in 2007-2011. Neuro-oncology 16(Suppl 4):1-63. https://doi. org/10.1093/neuonc/nou223

Pirtoli L et al (2009) The prognostic role of Beclin 1 protein expression in high-grade gliomas. Autophagy 5:930-936

Qi CC et al (2015) Antidepressant effects of abscisic acid mediated by the downregulation of corticotrophin-releasing hormone gene expression in rats. Int $\mathbf{J}$ Neuropsychopharmacol. https://doi. org/10.1093/ijnp/pyu006

Ribes-Navarro A, Atef M, Sánchez-Sarasúa S, Beltrán-Bretones MT, Olucha-Bordonau F, Sánchez-Pérez AM (2019) Abscisic acid supplementation rescues high fat diet-induced alterations in hippocampal inflammation and IRSs expression. Mol Neurobiol 56:454-464. https://doi.org/10.1007/s12035-018-1091-z

Sami A, Karsy M (2013) Targeting the PI3K/AKT/mTOR signaling pathway in glioblastoma: novel therapeutic agents and advances in understanding. Tumour Biol 34:1991-2002. https://doi. org/10.1007/s13277-013-0800-5

Scarfi S et al (2008) Cyclic ADP-ribose-mediated expansion and stimulation of human mesenchymal stem cells by the plant hormone abscisic acid. Stem Cells (Dayton, Ohio) 26:2855-2864. https:// doi.org/10.1634/stemcells.2008-0488
Shchors K, Massaras A, Hanahan D (2015) Dual targeting of the autophagic regulatory circuitry in gliomas with repurposed drugs elicits cell-lethal. Autophagy Ther Benefit Cancer Cell 28:456471. https://doi.org/10.1016/j.ccell.2015.08.012

Shipman L (2015) Glioma: repurposed drugs combined to amplify autophagy. Nat Rev Cancer 15:636. https://doi.org/10.1038/nrc40 33

Vanhee C, Batoko H (2011) Autophagy involvement in responses to abscisic acid by plant cells. Autophagy 7:655-656

Vicencio JM et al (2008) Senescence, apoptosis or autophagy? When a damaged cell must decide its path-a mini-review. Gerontology 54:92-99. https://doi.org/10.1159/000129697

Wasilewska A et al (2008) An update on abscisic acid signaling in plants and more. Mol Plant 1:198-217. https://doi.org/10.1093/ $\mathrm{mp} / \mathrm{ssm} 022$

Livingston WC (1976) (US3958025[P]) Abscisic acid tablets and process US

Yao KC, Komata T, Kondo Y, Kanzawa T, Kondo S, Germano IM (2003) Molecular response of human glioblastoma multiforme cells to ionizing radiation: cell cycle arrest, modulation of the expression of cyclin-dependent kinase inhibitors, and autophagy. J Neurosurg 98:378-384. https://doi.org/10.3171/ jns.2003.98.2.0378

Zhou N, Yao Y, Ye H, Zhu W, Chen L, Mao Y (2016) Abscisic-acidinduced cellular apoptosis and differentiation in glioma via the retinoid acid signaling pathway. Int J Cancer 138:1947-1958. https://doi.org/10.1002/ijc.29935

Zhou YY, Li Y, Jiang WQ, Zhou LF (2015) MAPK/JNK signalling: a potential autophagy regulation pathway. Biosci Rep. https://doi. org/10.1042/bsr20140141

Publisher's Note Springer Nature remains neutral with regard to jurisdictional claims in published maps and institutional affiliations. 